\section{Obituary Seymour M Antelman}

Neuropsychopharmacology (20I I) 36, 2788; doi: I0.1038/npp.201 I.208

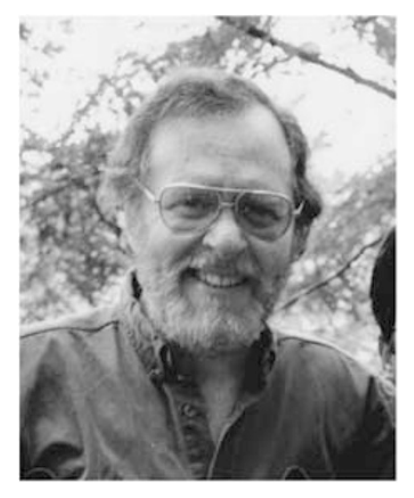

Dr Seymour (Sy) M Antelman, a neuroscientist and psychopharmacologist, died on June 10, following a short illness, at his Florida home. He left behind his wife Violeta and son Michael.

Sy, during his growing years, worked at the Museum of Natural History in New York City before joining the Illinois Institute of Technology at Chicago to pursue graduate studies in psychology. After Sy received his $\mathrm{PhD}$, he was awarded a National Institute of Mental Health Post-doctoral Fellowship to develop research career at the Karolinska Institutet in Stockholm.

Dr Antelman joined the University of Pittsburgh School of Medicine in 1973 as Assistant Professor of Psychiatry and Psychology, from where he was promoted to the full Professorship in 1990. He retired as Emeritus Professor of Psychiatry in 2001. During his tenure at Pittsburgh, he had appointment both in the Department of Psychology and Psychiatry, and as a Full Member of Pittsburgh Cancer Institute.

Among his many honors and recognitions, Dr Antelman was elected as Fellow of the American College of Neuropsychopharmacology, served on the Editorial Boards of several professional journals, and at the Scientific Advisory Board of the Scottish Rite Schizophrenia Research Foundation. His first proposal to NIMH received a perfect score of 100 in 1973. His Research Scientist Development Award (RSDA) application to NIMH received the top priority score in its first round; also it was the first at Western Psychiatric
Institute and Clinic (WPIC) to be awarded an RSDA in 1978. His research proposal to the Scottish Rite Schizophrenia Research Program finished first of 50 applications in 1978.

Dr Seymour Antelman was internationally known for the originality and importance of his work on the biological effects of stress and the effects of psychotropic drugs on the brain and behavior. The esteem in which his work was held is attested to by the fact that his work was published in many prestigious professional journals, including Science. He was invited to present his work at many leading educational and research institutions both in the United States and in Europe.

Dr Antelman is known mainly for (1) his work in developing an animal model of stress-induced overeating that was recognized throughout the world as the standard in the field; (2) his discovery that norepinephrine normally regulated dopamine; and (3) his discovery that the effects of drugs and stressors on both physiological systems and behavior grew with the passage of time following even a single exposure. This last work, which came to be known as Time-Dependent Sensitization, offered the potential for new ways of treating disease and to prevent chemical toxicity. This research received considerable attention. It was the subject of a New York Times article on 21 June 1988 and a program on the BBC's Overseas Service. Each of the findings mentioned was originally published in Science, and has been cited hundreds of times in scientific literature. His animal model of stress and overeating was patented and applied to develop commercial devices to induce farm animals to treat anorexia and gain weight.

Notwithstanding his remarkable achievements in the science of neuro-psychopharmacology, Sy excelled in art. All of us were impressed with his dramatic portraits of famous personalities and other paintings. His sense of home design was also remarkable, as it was well perceived by his friends who were hosted frequently in his homes.

\footnotetext{
Harbans $\mathrm{Lal}^{1}$

${ }^{1}$ Department of Pharmacology \& Neuroscience, University of North Texas Health Science Center at Fort Worth, Arlington, TX, USA E-mail: hblal@tx.rr.com
} 